Герман К.Э.

60-летию Алексея Николаевича Сорокина. М.: Издво ИА РАН. 2012. С. 571-590.

12. Герман К.Э. Хронология и периодизация культуры сперрингс // Тверской археологический сборник. 2002. Вып. 5. С. 264-273.

13. Филатова В.Ф. Мезолит бассейна Онежского озера. Петрозаводск: Изд-во КарНЦ РАН, 2004. $274 \mathrm{c}$.

14. Тарасов А.Ю. Адаптация к локальной сырьевой базе, технологическое развитие каменных индустрий и социальное развитие древних обществ: на примере культур Карелии периода неолита - раннего железного века // Адаптация культуры населения Карелии к особенностям местной природной среды периода мезолита - Средневековья. Петрозаводск: Издво КарНЦ РАН, 2009. Вып. 4. С. 111-134.

15. Витенкова И.Ф. Культура сперрингс // Археология Карелии. Петрозаводск: Изд-во КарНЦ РАН, 1996. С. 65-81.

16. Панкрушев Г.А. Мезолит и неолит Карелии. Л.: Наука, 1978. Ч. II. 164 с.

17. Песонен П.Э. Хронология и периодизация культуры сперрингс // Хронология и периодизация археологических памятников Карелии. Петрозаводск: Изд-во КарНЦ РАН, 1991. С. 65-85.

18. Иванищева М.В., Кулькова М.А., Иванищева Е.А. Радиоуглеродная хронология раннего неолита Нижней Сухоны и Юго-Восточного Прионежья // Радиоуглеродная хронология эпохи неолита Восточной Европы VII-III тыс. до н.э. Смоленск: Изд-во «Свиток». 2016. С. 397-409.

19. Иванищева М.В. К вопросу о времени и истоках гончарных традиций в раннем неолите Европейского Севера России // Неолитизация Северной Евразии: теории, гипотезы, факты: I междунар. интернетконф. 1 июля 2016 г. - 31 января 2017 г. Омск, 2017.

20. Иванищев А.М., Иванищева М.В. Поселение раннего неолита на Кемском озере // Тверской археологический сборник. Вып. 4. 2000. С. 297-305.

21. Верещагина И.В. Поселение Хепоярви в южной части Карельского перешейка // Неолит энеолит юга и неолит севера Восточной Европы. СПб.: Изд-во ИИМК РАН, 2003. С. 140-151.

Работа выполнена из средств федерального бюджета на выполнение государственного задания КарНЦ РАН.

\title{
THE SPERRINGS CULTURE (CURRENT STATE OF STUDY)
}

(C) 2018

German Konstantin Enrikovich, candidate of historical sciences, senior researcher of Archaeology Sector Institute of Linguistics, Literature and History of Karelian Research Centre of Russian Academy of Sciences (Petrozavodsk, Russian Federation)

Abstract. The following paper deals with the study of the Sperrings culture. More than a decade has passed since the last general publications on early Neolithic of Karelia. During this period, new sites of the Sperrings culture have been discovered and studied, first AMS-dating has been received from the ceramic fragments, monuments of the early Neolithic in the neighboring territories have been studied. As a result of two decades of the archaeological research in Karelia more than a dozen of new monuments were discovered and investigated, including poorly explored areas of the Northern Ladoga and Karelian isthmus. The Sperrings culture centre is the Onega lake basin, where more than 200 settlements are known. The existence period of the Sperrings culture in the Onega lake basin on the basis of AMS-dates is 5306-4250 cal BC. These data are also consistent with AMS-dating of bones of Koirinoya III settlement in the North Ladoga area. The Sperrings ceramics appeared on the territory of Karelia at the same time.

Keywords: Karelia lake Onega; lake Ladoga; North-Western Ladoga Region; Karelian Isthmus; Sperrings culture; chronology; AMS-Dating; early Neolithic; Sperrings ceramics; comb ceramics; Tudozero V settlement; Kemozero III settlement; origins of archaeological culture.

УДК 902.2, 903.2, 903-4

Статья поступила в редакцию 09.06.2018

\section{КЕРАМИЧЕСКАЯ ПОСУДА В КУЛЬТУРЕ БРОДЯЧИХ ОХОТНИКОВ КРАЙНЕГО СЕВЕРО-ВОСТОКА ЕВРОПЫ}

(C) 2018

Карманов Виктор Николаевич, кандидат исторических наук, заведующий сектором сохранения и популяризации археологического наследия Институт языка, литературы и истории Коми научного иентра УрО РАН

\author{
(2. Сыктывкар, Российская Федераџия)
}

\begin{abstract}
Аннотация. В статье обобщены и систематизированы первичные данные о керамической посуде неолита и энеолита Крайнего северо-востока Европы. Автор проанализировал сведения об археологических контекстах керамической посуды, ее количественные (число емкостей в каждом комплексе) и качественные (форму, пропорциональность и объем сосудов) характеристики. Для оценки познавательной возможности доступных источников использован критический анализ. В результате прослежены динамика количественных и качественных параметров керамической посуды в течение VI - первой половины II тыс. до н.э. и их различия в связи с различной культурной принадлежностью. Установлено, что в первой половине V тыс. до н.э. керамика в виде наборов посуды разных объемов и видов становится неотъемлемой частью повседневности бродячих охотников региона. В связи с их образом жизни потребность в керамике была ограниченна: среднее число одновременно использованных сосудов в среднем 3-4 емкости на контекст. При этом преобладают простейшие формы - круглодонные горшки объемами до 25 л и мискообразная посуда до 2,5 л.
\end{abstract}


Керамические традиции, представленные в регионе, связаны с культурами, имеющими истоки на разных сопредельных территориях лесной зоны Восточной Европы и Западной Сибири, поэтому очевидна универсальность выработанных для этой зоны привычных форм, объемов и, вероятно, способов использования керамической посуды. Полученные данные могут служить материалами для разработки проблемы распространения древнейшей керамики, для оценки роли и определения места керамической посуды в материальной культуре первобытного населения.

Ключевые слова: первобытная культура; археология; археологические источники; археологический контекст; памятник археологии; место обитания; стоянка; поселение; слабо углубленное жилище; скопление; очаг; неолит; энеолит; Крайний северо-восток Европы; керамика; керамическая посуда; форма емкости; объем емкости.

\section{Введение}

Уже стало азбучной истиной суждение о значительной роли археологической керамики в изучении первобытной культуры как массового вида источника с хорошей сохранностью и как первого искусственного материала, изготовленного с помощью сложной технологии. Отечественные археологи не только наделили керамическую посуду таксономической ценностью, но и определили ее основным признаком неолита. В связи с этим внимание исследователей сосредоточено преимущественно на возможности керамики как источника информации о древних гончарных технологиях, происхождении культур, их развития и хронологии. Наиболее активно развивается историко-культурный подход и различные способы применения естественнонаучных методов [1, с. 11-36]. Главным образом они нацелены на реконструкцию древних гончарных технологий и получения на этой основе данных для моделирования культурных процессов.

В меньшей мере в литературе представлены попытки изучения керамической посуды как части материальной культуры во взаимосвязи с образом жизни первобытных коллективов и другими ее явлениями; попытки объяснения глобальности керамики, определения ее места и роли в конкретных культурах разных регионов [2; 3, с. 104-113]. Это обусловлено, прежде всего, состоянием источников: фрагментарностью сосудов, многократностью посещений территорий в древности и сложным составом большинства памятников. Часто по имеющимся данным невозможно определить важнейшие показатели: объем емкостей, количество сосудов, пространственные характеристики их контекста, а также связь типов керамической посуды с определенной группой населения и т.п. И есть опасность, что набирающее в последнее время обороты применение видов изотопного анализа будет использовать именно такие данные и, главное, это способно отвлечь археологов от решения собственных проблем. Поэтому очень важно обратиться прежде всего к обобщению и систематизации доступных нам археологических источников и их критическому анализу.

В этой статье мы обращаемся к изучению керамической посуды как явления материальной культуры в среде бродячих охотников таежной зоны Крайнего северо-востока Европы (современная территория Республики Коми и восточных районов Архангельской области или бассейны р. Печоры, р. Мезени и правобережной части бассейна р. Сев. Двины с p. Вычегдой). Эта территория занимает северо-восточную часть Восточно-Европейской равнины и примыкает на востоке к Уральскому хребту. Она обширна: ее площадь превышает размеры многих ев- ропейских стран (например, Германии или Польши). С палеолита и до позднего периода эпохи железа (в историческом измерении - периода русской колонизации) его населяли группы охотников, ведущих очень подвижный образ жизни. В течение всего этого периода могли меняться хозяйственные циклы, направления миграций и культурных контактов, их интенсивность, но в основе системы жизнеобеспечения этого первобытного населения всегда были присваивающее хозяйство и экстенсивный путь освоения территории [4, с. 91-560]. В некоторых частях региона они практиковались вплоть до начала ХX в. При этом керамическая посуда здесь уже в первой половине VI тыс. до н.э., наравне с более южными и плотно населенными регионами и оседлыми обществами, становится неотъемлемой частью материальной культуры. В связи с этим закономерно обращение к определению ее роли в культуре бродячих охотников, особенно к появлению древнейшей керамики в этой среде и ее дальнейшему распространению и использованию. Ведь действительно интересен вопрос, который иногда задают себе исследователи: а насколько необходимо и рационально использование громоздкой и хрупкой керамической тары и затрат времени на ее изготовление очень мобильным населением? И как оно могло включить в свой обиход этот «якорь», не меняя привычного образа жизни? [5, р. 779-792]. Как такие общества преодолевали препятствия, связанные с необходимостью изготовления керамики; ограничивает или препятствует керамическая посуда степень мобильности; влияет ли сама мобильность на форму и размеры посуды [2, p. 729]. Почему закономерно ставший непременным и необходимым для земледельческих и оседлых обществ атрибут стал таковым для присваивающих хозяйств [3, с. 104-113] и, применительно к нашему случаю, бродячих охотников Крайнего Севера? Ведь особенно таежная зона богата на различные натуральные и легкие материалы (дерево, береста, и повсеместная кожа), которые прекрасно удовлетворяли потребности человека в предшествующее появлению керамики время. Можно даже привести примеры из быта коми охотников XIX - нач. XX в.: «при ночлеге вне избушки в берестяной посуде иногда даже варили пищу, в одном чумане можно было варить до трех раз» [6, с. 40]. Но распространение керамики происходит рано или поздно повсеместно в различных географических районах, и, конечно, это явление «никак не объяснить ни детскими игрушками, ни необходимостью сохранения лесных ягод или орехов, ни потребностями создания запасов чего бы то ни было на зиму, ни необходимостью термической обработки даров леса» [3, с. 110]. Поиск этого объяснения еще впереди. Но для того чтобы попытаться найти его, в первую очередь нужно описать 
само явление. Для этого необходима прежде всего характеристика самой керамической посуды по универсальным для нее параметрам, которые, с одной стороны, давали бы возможность сопоставления материалов разных регионов на едином основании, с другой - характеризовали особенности природного и культурного фона.

Очевидно, что для посуды, суть которой служить емкостью в обыденной и ритуальной практике, таковыми будут объем и форма. На интенсивность и характер ее использования конкретными сообществами указывает количество сосудов в одномоментно отложенном комплексе. А география и контекст обнаружения керамики позволяют учесть региональные и культурные особенности ее использования. То есть это набор характеристик, доступных прежде всего археологу. Однако мы не ограничимся только древнейшей керамикой региона, поскольку нам важно узнать, какова инерция этого явления, по какому сценарию оно развивалось дальше. Поэтому использованы источники по неолиту и энеолиту региона или VI - перв. пол. II тыс. до н.э. Кроме того, на этом этапе исследования важно определить познавательные возможности источников для решения поставленной задачи: попытаться выявить информационные «ловушки», которые ненамеренно «расставили» первобытные люди и время. Надеемся, что эти необходимые первичные данные с поступлением новых сведений позволят приблизиться к достоверной оценке роли и места изучаемого явления в первобытной культуре таежных охотников. При этом пока не задействованы в полном объеме методы изучения гончарства как технологии. Ведь наличие посуды в известных контекстах подразумевает ее успешное изготовление и использование, несмотря на различия в составах формовочной массы, способах лепки, обработки поверхности, обжига и т.п. Поэтому для решения задачи имеющиеся данные о таких характеристиках сосудов (помимо объема и формы) привлекаются в рамках оценки состояния источников и условий их формирования. Также на этом этапе не привлекаются сведения об особенностях орнаментации, так как в контексте изучаемой проблемы она вторична и развитые системы декора возникают позднее самой посуды: древнейшая керамика повсеместно не орнаментирована вовсе или имеет сравнительно «бедный» декор. Кроме того, этот показатель очень изменчив не только при сравнении материалов разных регионов, но и зачастую в пределах одномоментно отложенного комплекса.

\section{Характеристика источников}

Для этой работы нами собраны и проанализированы сведения об остатках 141 места обитания и пребывания неолита и энеолита Крайнего северо-востока Европы (рис. 1). Из них 118 - это следы слабо углубленных жилищ, остальные - открытых стоянок или наземных сооружений. Единственный критерий отбора - их полное изучение и возможность определения границ контекстов в пространстве, что позволяет корректно судить о количественных параметрах коллекций и пространственной организации мест обитания. Этому способствовали методика раскопок видимых на поверхности объектов и сравнительно малая площадь скоплений. Согласно оформленным культурно-хронологическим схемам они представ- ляют ранний (памятники типа Черноборской III, Дутово 1, Черная Вадья, Эньты IA, камская культура) и развитый (льяловский тип) периоды неолита; финального неолита и энеолита (чужъяёльская культура или ортинский тип; чойновтинская или гаринская культуры, включая памятники типа Галово II; ниремский тип и комплексы пока с неопределенной культурной атрибуцией (например, Синегорье I). Вклад в их изучение и публикацию материалов внесли В.Е. Лузгин [7], В.С. Стоколос [8-10], Э.С. Логинова [11-14], К.С. Королев [15, с. 27-50], В.А. Семенов и В.Н. Несанелене [16], И.В. Верещагина [17, с. 121-128; 18, с. 29-46], Л.Л. Косинская [19-22], Ю.В. Паршуков [23; 24], В.Н. Карманов [25; 26]. В качестве фоновых источников использованы некоторые материалы, которые не отвечают ряду требований (например, недостаточная изученность), но способны дать дополнительные и достоверные сведения по изучаемой проблеме.

В результате изучения памятников Крайнего северо-востока Европы стало ясно, что они представляют преимущественно остатки сезонных мест обитания, которые действовали в холодное, гораздо реже в теплое время года $[8$, с. 92,$93 ; 27$, с. $23-41 ; 21$, с. $123 ; 28$, с. $56 ; 18$, с. $119-128 ; 29$, с. $419-428]$. По мнению всех исследователей, они оставлены группами численностью в среднем от 5 до 15 человек. Обо всем этом свидетельствует сравнительная малочисленность артефактов и экофактов в коллекциях; малая мощность культурных слоев и культуровмещающих отложений; особенности домостроительства (крайняя простота архитектуры сооружений, очень редкие случаи многократного использования построек и ремонта или перестройки жилищ); топография (удаленность от источников воды) и обширная география однотипных и/или синхронных комплексов. Эти же данные наряду с доступным для изучения орудийным набором свидетельствуют о преобладающей роли охоты в системе жизнеобеспечения коллективов, их высокой мобильности.

Большинство памятников неолита и энеолита на Крайнем северо-востоке Европы приурочено к поверхностям рельефа, созданного эоловыми песками, покрывающего компоненты речного ландшафта или прикраевые участки коренных берегов рек. Ситуации нахождения информативных контекстов этого времени в озерно-болотных и пойменных отложениях немногочисленны: Половники II [30, с. 132-133] и Пезмог IV [31, с. 137; 32, р. 733]. Эти места пребывания могли существовать на молодой пойме у реки. Возможно, что таких стоянок было гораздо больше, но постоянные миграции речных русел оставили им мало шансов на сохранение и доступность их изучения. Большинство мест обитания было удалено от синхронных им русел рек или старичных озер. При этом нужно иметь в виду, что в первобытности это расстояние могло быть и больше, чем мы наблюдаем сейчас. Наряду с другими данными (залегание остатков преимущественно в пределах сооружения, интенсивная утилизация кремневого сырья и изделий из него) это лишний раз указывает на зимний период функционирования большинства изученных комплексов.

Особенности топографии мест обитания и пребывания, их геоморфологической приуроченности, ограничили источниковую базу артефактами и ма- 
нупортами из минеральных пород, кальцинированными костями животных и следами земляных структур и их компонентов. Изделия из металла крайне редки на памятниках энеолита и даже в последующие периоды. Также единичны янтарные поделки и прочие дошедшие до нас предметы неутилитарного назначения: подвески из плоских галек, фигурные кремни, керамические фигурки и диски, что также характеризует простоту повседневного быта первобытных охотников.

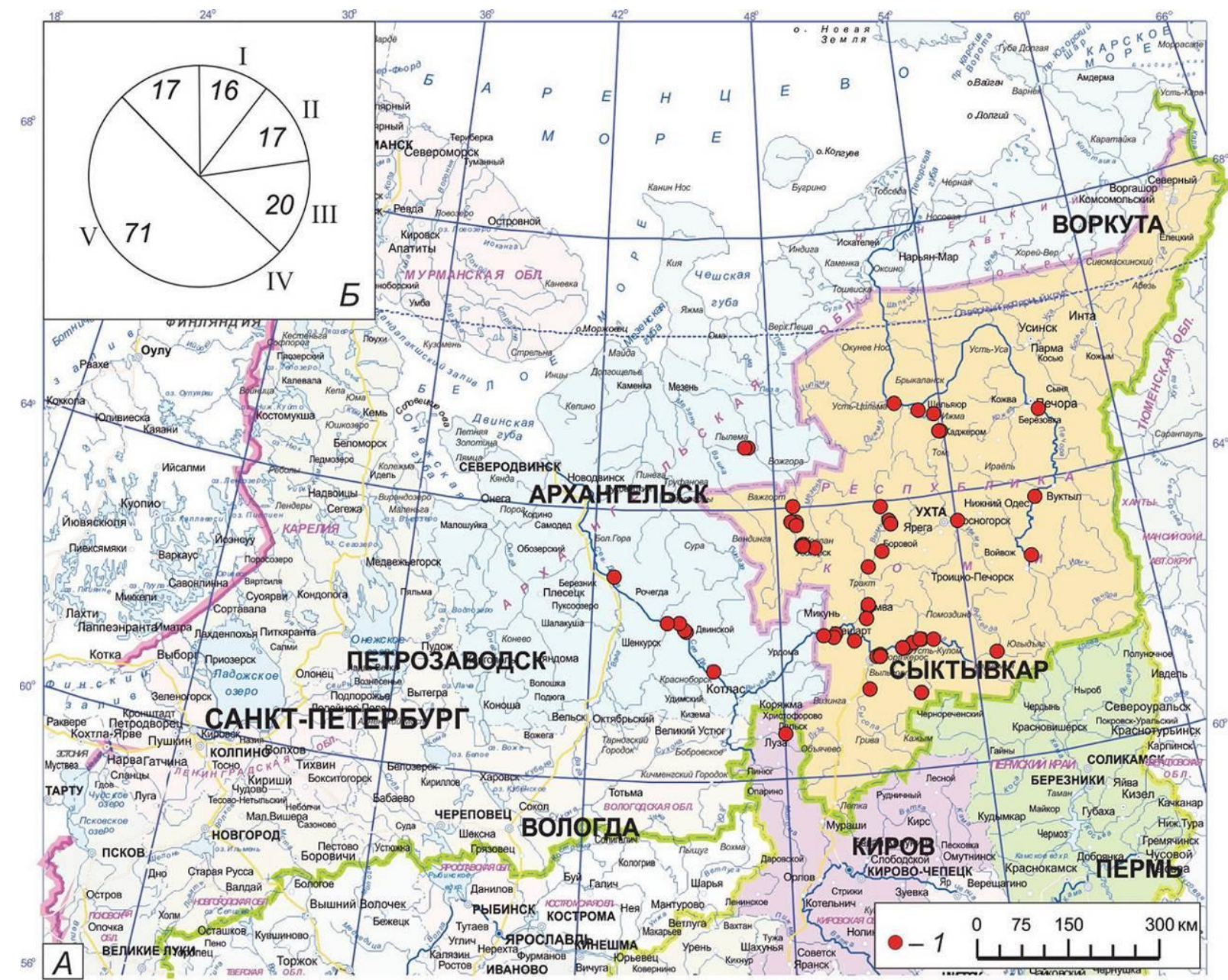

Рисунок 1 - Район исследования на карте северо-западного федерального округа $(A)$.

1 - памятник археологии. Количественное распределение изученных контекстов по их культурнохронологической атрибуции (Б). I- ранний неолит (памятники разной культурной принадлежности; II- средний неолит (памятники с гребенчато-ямочной керамикой, преимущественно льяловского типа); III - финальный неолит - энеолит (чужъяёльская культура и сопряженные с нею комплексы); IV - энеолит (чойновтинская или гаринская культура, включая памятники типа Галово II); $V$ - прочие памятники энеолита (ниремский тип, типа Синегорье 1 и др.)

\section{Характеристика керамической посуды}

Количественнье данные

На этом этапе исследований учтены данные о 765 сосудах из 131 контекста. Первый показатель - количество керамических емкостей в каждом из них указывает на интенсивность их использования первобытными коллективами (рис. 2). При этом на наше представление об этом влияет сохранность керамики. В качестве региональных особенностей укажем на негативное воздействие корневой системы деревьев, регулярные сезонные промерзания и оттаивания грунтов, их промывание талыми и дождевыми водами. Особенно активно разрушаются сосуды, изготовленные из глиняного теста с обильной дресвой, и т.н. пористая керамика, имеющая примесь органики и/или раковины. Последняя выщелачивается в кислой среде подзолистых почв. Лучшей сохранностью отличается посуда с минеральными мелкотолчеными и однородными примесями, что будет показано ниже.
Следы использования керамики не по прямому назначению ее пользователями немногочисленны: 1) применение в качестве примеси к глиняному тесту (Зубово); 2) изготовление округлых дисков с центральным отверстием (Шиховское II; Эньты II, VII; Ниремка I, жилище № 12); 3) намеренный нагрев обломков для обогрева помещения (Ваднюр I, жилище № 7). Другое обстоятельство, влияющие на имеющиеся у нас сведения, - ремонт сосудов преимущественно крупных размеров, продлевающий срок их использования; пока учтено 30 случаев. Он производился следующим образом: на противоположных частях лопнувшего сосуда изготавливали парные сквозные отверстия, по которым обломки сшивались, а шов и отверстия покрывали клеем, изготовленным, вероятно, из смолы или березового вара. Однако мы не можем утверждать то, на каком этапе возникала необходимость ремонта - после его использования (от термического удара или неосторожного обращения) или после неудачного обжига. Изучены также контексты, свидетельствующие о намеренном пере- 
мещении обломков разных сосудов в самой земляной структуре (Ваднюр I, жилище № 5, № 7) или их выносе за пределы постройки (Мучкас; Ваднюр I, жилища № 5, № 7; возможно, Чойновты II, жилище № 14).

В любом случае мы вынуждены использовать только сохранившиеся данные (рис. 2), а они таковы. Среди изученных комплексов неолита и энеолита не содержали керамики всего 10. Они раскопаны полностью, и поэтому исключена возможность ее нахождения в другой функциональной зоне. Зато часть из них представляет явные остатки кремнеобрабатывающих мастерских (например, Керос; Пезмогты 2А и 2Б; возможно, Пезмогты 4А; Евдино III, жилище № 2), летних временных стоянок с мобильными жилищами или хозяйственных построек (Ниремка I, пункт 6; Угдым IB; Эньты VI, жилище № 2); для некоторых контекстов ее отсутствию пока нет объяснения (Ревью I, Чужъяёль II).

В остальных ситуациях общее количество керамических емкостей в каждом контексте редко превышает 8-10 сосудов. Коллекции древнейшей керамики содержат при этом не более шести горшков, а в среднем 1-2. Системно большим количеством выделяются памятники с гребенчато-ямочной керамикой среднего неолита и в большей степени чужъяёльская традиция (рис. 2: $I V, V$ ). Это, скорее всего, объясняется лучшей сохранностью керамики, изготовленной из глины с минеральными примесями. Однако не исключена и особенность чужъяёльской культуры в использовании посуды, которая, как будет показано ниже, отличается и по другим параметрам. Это важно, потому что нужно в будущем решить вопрос: правомерно ли брать за эталон ее комплексы и распространять данные по ним на другие периоды, за исключением раннего неолита.

При изучении количественных данных следует обратить внимание еще на две ситуации: Эньты I (ранний неолит, эньтыйский тип, 40 сосудов) [11, c. 11-14; 33] и жилище № 3 поселения Ошчой V (энеолит, чужъяёльская культура, 29 сосудов) [8, c. 79]. Первый комплекс уникален во всех отношениях: по своим размерам, количеству очагов и хозяйственных ям он превосходит все известные в регионе памятники каменного века и энеолита. Его каменный инвентарь отличают геометрические микролиты в форме трапеций (поперечно-лезвийных наконечников), что не характерно для неолита лесной зоны Восточной Европы. При этом керамическая посуда имеет наибольшее соответствие в материалах 2-го или 3-го этапа верхневолжской культуры. Другой такой аналогичный контекст - Ревью I - имеет меньшие размеры, а главное, вовсе не содержит керамики [34]. Поэтому уникальность памятников эньтыйского типа еще ждет своего объяснения.

Комплекс жилища № 3 Ошчой V содержит 29 сосудов, включая 12 емкостей объемом менее 0,5 л рекордное число среди всех изученных контекстов. Вся посуда имеет хорошую сохранность, в том числе некоторые горшки восстановлены в полном объеме [8, с. 82]. Еще одна необычная деталь комплекса овальное блюдо, промазанное охрой, и два шаровидных сосуда разных размеров - формы, совершенно не свойственные керамической посуде региона. Можно привести всего два примера овальных в плане сосудов: миниатюрная чаша из жилища № 6 поселения Ошчой I [8, рис. 57: 4] и сосуд стоянки Усть-Комыс I [16, с. 115-116, рис. 69: 8]. Отличается жилище № 3 и своей топографией: оно занимает самое высокое центральное место среди однокультурных с ним построек поселений Ошчой I и III. Все это указывает на необыденное использование этой постройки.
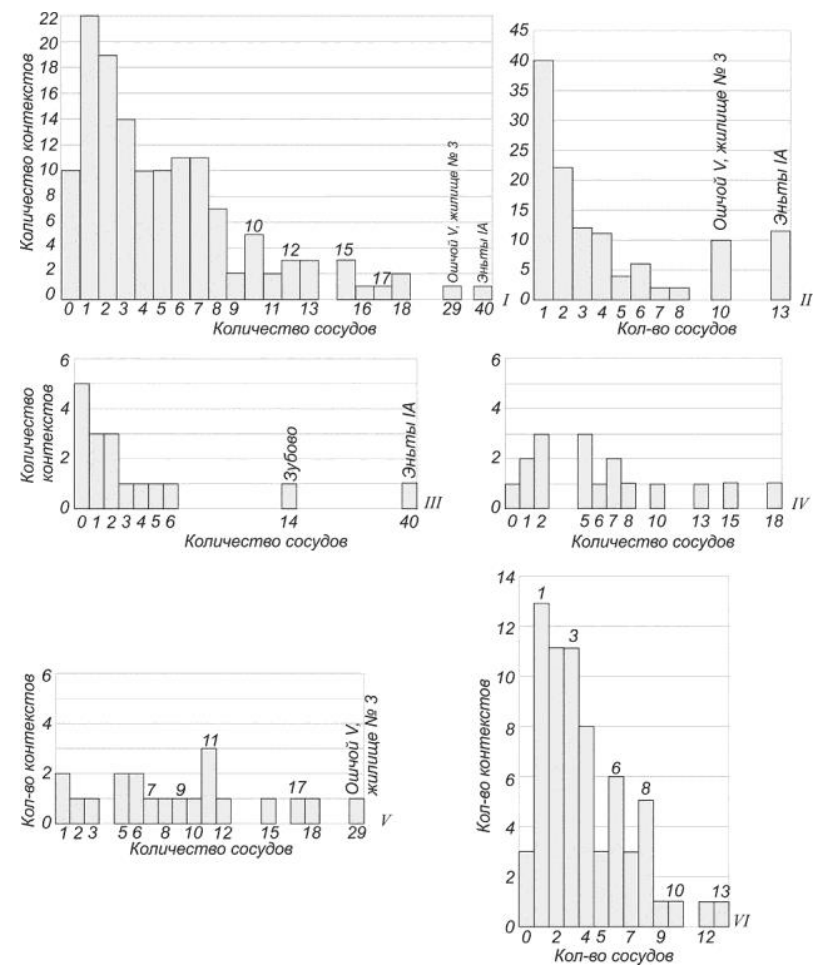

Рисунок 2 - Количество керамических сосудов в изученных контекстах. $I$ - общее количество; II- общее количество с учетом сохранности и состояния залегания в слое; III-VI- количество согласно культурно-хронологической атрибуции: III- ранний неолит (памятники разной культурной принадлежности; IV- средний неолит (памятники с гребенчато-ямочной керамикой, преимущественно льяловского типа); $V$ - финальный неолит - энеолит

(чужъяёльская культура и сопряженные с нею комплексы); VI- энеолит (чойновтинская или гаринская культура, включая памятники типа Галово II)

Исходя из простого подсчета числа сосудов, мы можем определить лишь примерное количество использованных емкостей в период жизни коллектива на определенном месте. С какой интенсивностью они выходили из строя, сколько их использовалось одновременно - эти данные не учитывают. Вероятно, более близок к реальности результат сохранности керамики в связи с особенностями ее залегания. При этом предполагается, что ее нахождение в развалах или в компактных скоплениях - это и есть последние использовавшиеся и оставленные на покинутом месте емкости. Однако и в этой ситуации мы можем иметь дело с ненамеренной сортировкой источника в древности. Она может быть обусловлена объемом и функцией сосудов и соответственно интенсивностью их использования и рисками для ее сохранности, связанными с этим. Посуда небольших размеров для термической обработки продуктов (не только питания) наиболее подвержена риску быть сломанной. Этому способствует и то, что ее чаще переносили с места на место. Например, миниатюрные чашки и миски мы редко находим в целом состоянии, они, 
как правило, фрагментированы, а их части чаще других можно найти в остатках очагов. Напротив, крупные сосуды могли устанавливаться на какое-то время стационарно, и их разрушение связано уже с археологизацией контекста.

Важные показатели для количественной характеристики комплексов - соотношение основной площади мест обитания и пребывания (жилищ, скоплений) и числа керамических сосудов в них, а также связь количества керамических емкостей и очагов. Предполагается, что чем крупнее жилище, тем большее число людей оно могла вмещать или его площадь определена размером коллектива, для которого оно сооружалось. Очаг воспринимается как элемент хозяйства и применяется правило «1 очаг 1 малая семья». Все эти данные используются для оценки численности первобытных сообществ, и на этой же основе иногда вычисляется количество горшков на одну семью [21, с. 126,$127 ; 35$, с. 71-78]. Эти показатели рассчитаны и для изучаемых материалов, результаты представлены на рисунке 3 .
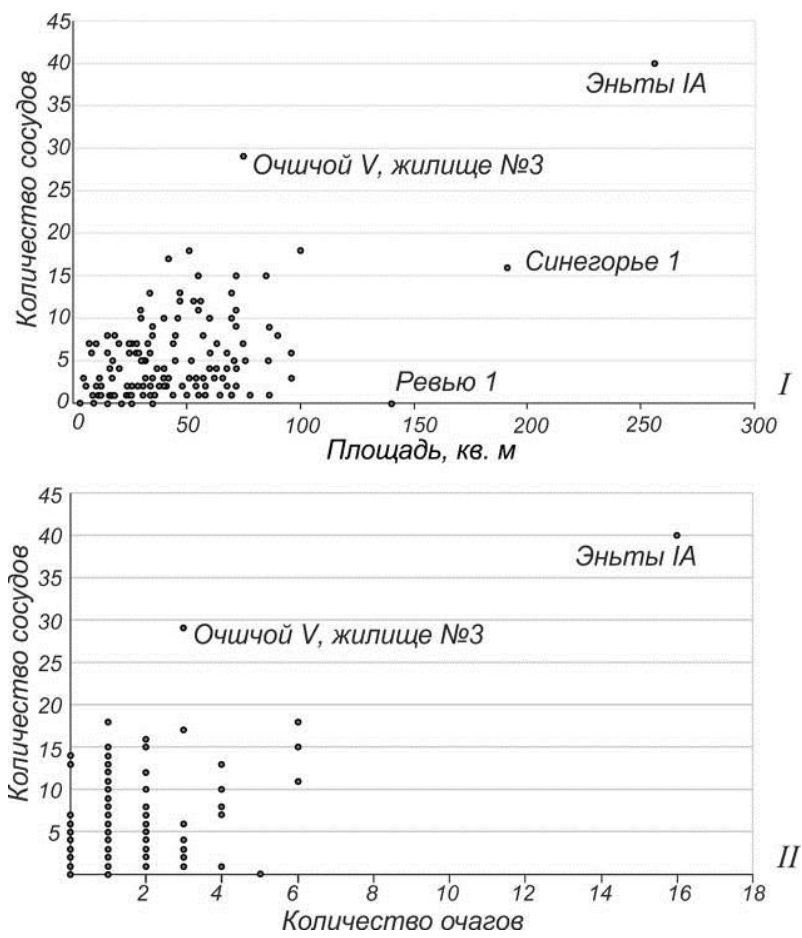

Рисунок 3 - Зависимость количества сосудов от площади жилого пространства ( $I)$

и количества очагов в каждом из контекстов (II)

Оба графика показывают слабую зависимость числа сосудов от площади жилищ и скоплений и от количества очагов в их контекстах. Вероятно, это связано с учетом всей совокупности посуды. В дальнейшем необходимо по возможности отделить сосуды очень малых и малых объемов, явно связанных с индивидуальным потреблением, ритуальной практикой и, возможно, т.н. ученическими образцами. И попытаться произвести расчет по емкостям для коллективного потребления или приготовления пищи. В какой-то мере искажение информации связано с тем, что не во всех контекстах исследователи могли обнаружить очаги (или не все из них), которые, как правило, не были конструктивно оформлены и из-за кратковременности (или других особенностей) их использования не оставили никаких следов.

\section{Пространственные характеристики}

К сожалению, не все исследователи приводят детали особенностей залегания керамики, вероятно, по причине отсутствия заслуживающих внимания обстоятельств. Приведем те сведения, которые удалось найти в литературе и архивных источниках, а также собственные полевые наблюдения. Так, Л.Л. Косинская сообщает об обычном расположении сосудов в жилищах Ниремки I «в углу полуземлянок у входа на нарах, где они вкапывались в песчаную почву» [21, c. 125]. В.С. Стоколос так объяснял ситуацию залегания горшков в виде развалов, закрывающих вход в жилищах № 2, № 3 и № 5 поселения Чужъяёль I: сосуды могли храниться «на полке над входом ... высота предполагаемой полки над полом была небольшой...», во время разрушения постройки они падали и ломались $[8$, с. 22, 27, 37]. В жилище № 3 поселения Ошчой V сосуд обнаружен в раздавленном состоянии вверх дном «на уступе восточной стенки жилища», от него сохранились все фрагменты [8, c. 82]. Э.С. Логинова в жилище № 2 поселения Эньты VII зафиксировала невысокую «полку» из материкового песка, на которой могла располагаться посуда [36, л. 4]. В исследованных автором контекстах неолита (Пезмогты $1,3,4,5)$ и энеолита (Угдым ІБ и ІГ) компактные скопления обломков сосудов разных размеров залегали у стенок котлованов построек или в их углах, на уровне обитания и без следов какихлибо углублений. В преобладающем числе ситуаций исследователи также не указывают на наличие свидетельств использования каких-либо конструкций и углублений.

Очень редки сведения о специальных ямах для керамических емкостей. Так, Э.С. Логинова обращает внимание на яму № 5 поселения Эньты I (ранненеолитический комплекс), в которой найдены обломки двух сосудов: фрагменты одного из них залегали согласно стенкам ямы, повторяя ее очертания. На дне углубления лежало плоское донце горшка. При этом венчики располагались внутри торцом вниз, вместе с фрагментами второго сосуда [33]. Остальные сосуды этого памятника исследователь обнаружила на окраинах пятна находок общей площадью до 256 м $^{2}$ вне прямой связи с многочисленными ямами и очагами этого комплекса. Также в яме № 1 стоянки раннего неолита Дутово 1 залегали обломки керамического сосуда наряду с фрагментами кальцинированных костей и гальками. Но размеры ямы здесь значительно превышают объем этой небольшой емкости [25, рис. 12$]$. Обычно же речь идет о находках небольшого числа фрагментов керамики в ямах за пределами жилищ [например: 8, с. 72, 123].

Определено три основных состояния залегания обломков сосудов на плане (не учитывались контексты с ее единичными находками): 1) рассеянно (22 случая); 2) скоплениями и рассеянно (37); 3) скоплениями, в т.ч. в виде развалов (45). Последняя ситуация выделена условно, поскольку во всех контекстах присутствует определенное число обломков керамики, рассеянных по площади. По отношению к компонентам структуры фиксируется преимущественное расположение скоплений, в т.ч. развалов, вблизи стенок котлованов построек, у входов-выходов, гораздо реже в нишах. При этом лишь на двух местонахождениях (Дутово 1 и Эньты 1А) сосуды приурочены к ямам, в остальных случаях их фрагменты со- 
средоточены в придонной части котлована постройки или на уровне обитания. Зафиксированы ситуации нахождения мелких, порой единичных обломков керамики среди остатков и следов кострищ, но их точное количество установить не удалось из-за частого отсутствия сведений в литературе и архивных источниках. Явных случаев учтено всего 12. Еще необходимо учитывать форму емкостей (см. ниже): будучи наполненными, сосуды известных нам форм требовали их установки в углублении в грунте или на специальной опоре (пустыми их могли укладывать вверх дном). Остатки и следы изученных очагов таковы, что не позволяют утверждать о наличии углублений или других конструктивных элементов для этого. Такие свидетельства либо не сохраняются, либо не могут быть зафиксированы из-за дальнейших деформаций грунта и разрушения жилищ. Еще вариант - использование песчаных «подушек», использование которых можно только предположить.

Из анализа ситуаций распределения обломков керамической посуды, ее сохранности и пространственного соотношения с компонентами структур можно сделать три основных вывода. 1. Сравнительно хорошая сохранность сосудов в условиях малых площадей построек и скоплений указывает на непродолжительность обитания в них и, возможно, однократность их посещения. 2. Преимущественно развалы и скопления сосудов располагаются на периферии сооружений: у стенок котлованов построек, их углах и у входов-выходов; при этом связь с местами разведения огня слабее. 3. Подсчет наиболее сохранившихся емкостей, залегающих в виде скоплений обломков, развалов, позволяет сократить число одновременно используемых сосудов до 1-2, реже 3-4 на объект (рис. 2: II).

\section{Форма и объем}

Принципиальная региональная схема развития основных форм керамической посуды в неолите энеолите представлена на рисунке 4.

Древнейшую керамику характеризуют плоскодонные сосуды, найденные на стоянках Прилукская [37, с. 31-36], Конещелье [9, с. 80-94], Зубово [38, c. 66-71], Угдым IA [29, рис. 9, 10]. Исключение составляет горшок из контекста Пезмог IV [25, рис. 51] и, возможно, Кочмас Б [39, с. 10-12]. Уникальна своими формами керамика Эньты IA $[11$, рис. 6,7 ; 25, рис. 43-47]: ее представляют остродонные горшки и сосуды с донцами-опорами. Последние - это своеобразный компромисс между двумя видами: древнейшей плоскодонной и привычной для последующих периодов круглодонной, поскольку в основе сосудов Эньты IA - полуяйцевидный приземистый котел, но со сравнительно небольшой опорой. Впоследствии форма сечения горшков в виде параболы абсолютно преобладает в течение всего изучаемого времени. Так, керамика с уплощенными днищами найдена лишь на двух памятниках энеолита: стоянка Бож-ты и Синегорье 1 [40, с. 40-42, рис. 9, 10].

Важный показатель формы сосудов - их общая пропорциональность, которая определяется отношением высоты к максимальному диаметру его верхнего края или тулова. Соответственно, чем этот показатель меньше, чем ниже и шире посуда. Изученная керамика региона включает три основные группы по этому показателю (табл. 1): низкие (общая пропорциональность менее 0,3534$)$, средние низкие $(0,3535-$ $0,7069)$ и средние $(0,707-1,413)$ сосуды $[41$, с. $154-$
155]. В литературе зачастую они называются мисками или блюдами и горшками. В коллекциях исследуемого региона преобладают горшки, причем как во всей совокупности керамики, так и в культурнохронологических группах. Есть всего один сосуд, представляющий чужъяёльскую культуру, который может быть отнесен к четвертой группе средних высоких сосудов (пропорциональность 1,413-2,827). Функциональные части в изученных емкостях не выделяются. А слабый изгиб в профиле стенки в верхней части некоторых горшков чужъяёльской, в меньшей мере, гаринской традиции - скорее декоративный элемент, если судить по общей пропорциональности и профилировке стенок сосудов. Вероятно, такую же роль играет оформление венчиков.

Для настоящей работы измерен объем 182 емкостей или $23,8 \%$ от всей совокупности учтенной керамики (табл. 2; рис. 4). Их число можно будет увеличить после непосредственного изучения коллекций с учетом полученных для региона данных об их наиболее вероятных пропорциях. Для измерения объема реконструированных в разной мере сосудов использовалась техника М.П. Грязнова [42, с. 313317], но с более дробным делением размеров цилиндров высотой 1 см. Это в какой-то мере повысило точность измерений. Но при этом все равно приходилось определять диапазоны объемов, поскольку часто была недоступна информация о днищах, хотя эта часть емкостей из-за особенностей их формы в меньшей степени влияет на объем по сравнению с диаметром и углом наклона стенок сосуда. При этом, даже имея сравнительно большой фрагмент, особенно у крупных емкостей, нельзя быть уверенным в адекватности определения их диаметров из-за неправильности окружности лепного горшка по венчику. Поэтому все измерения усреднялись, что все же давало основание отнести сосуд к той или иной размерной группе (табл. 2), которые могут иметь свое функциональное назначение: 1) от 0,1 до 2,5 л - посуда для индивидуального потребления напитков и пищи; 2) от 2,5 до 10 л - для коллективного приготовления и/или потребления пищи; 3) от 10 до 25 л для содержания регулярно используемых жидкостей и других пищевых продуктов; 4) от 25 л и более для длительного выдерживания или хранения пищевых продуктов [41, с. 125]. Существуют и более дробная группировка сосудов по объему [43, с. 403], но для задач нашего исследования и объема естественной выборки измеренных сосудов она чрезмерна. Хотя нужно оговориться, что функцию емкости того или иного объема нужно каждый раз обосновывать на конкретном материале. Например, есть мнение о том, что керамика в неолите лесной зоны Восточной Европы никогда не использовалась для хранения [35, с. 133].

Они свидетельствуют о преобладании емкостей до 10 л, т.е. предположительно для индивидуального и коллективного потребления и приготовления пищи. Исключение составляет чужъяёльская традиция, для которой характерно сравнительно большое количество сосудов вместимостью более 25 л. Среди ранненеолитических материалов выделяются круглодонные горшки закрытой формы камской культуры местонахождения Пезмог IV и Кочмас Б, которые имеют объемы от 36 до 63 л. Если в отношении материалов Кочмас Б можно сомневаться в столь раннем возрасте, то время отложения культурных остатков на местонахождении Пезмог IV установлено до- 
статочно убедительно [32]. Объяснение этому можно найти в возможных зауральских (западносибирских) истоках гребенчатых традиций [44, с. 36-38] в этой части Европы, т.е. мы видим образованную на другой территории форму, ставшей впоследствии привычной и для этой части таежной зоны. Материалы чойновтинской или гаринской культуры, включая

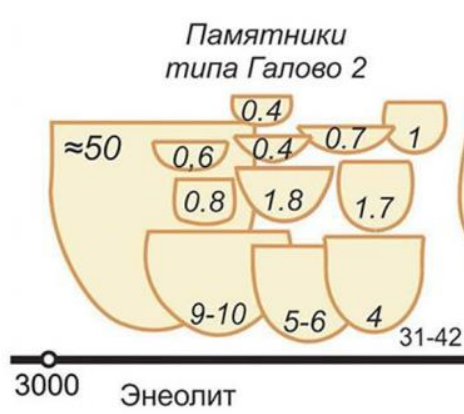

памятники типа Галово II, впечатляют очень высоким содержанием емкостей до 10 л. Здесь же сравнительно высока доля низких сосудов в виде мисок и чаш. При этом качество посуды (составы формовочных масс) одинаково и сохранность керамики в слое играет в этом случае не такую роль, как при сравнении материалов разных культур.

Чойновтинская

или гаринская культура
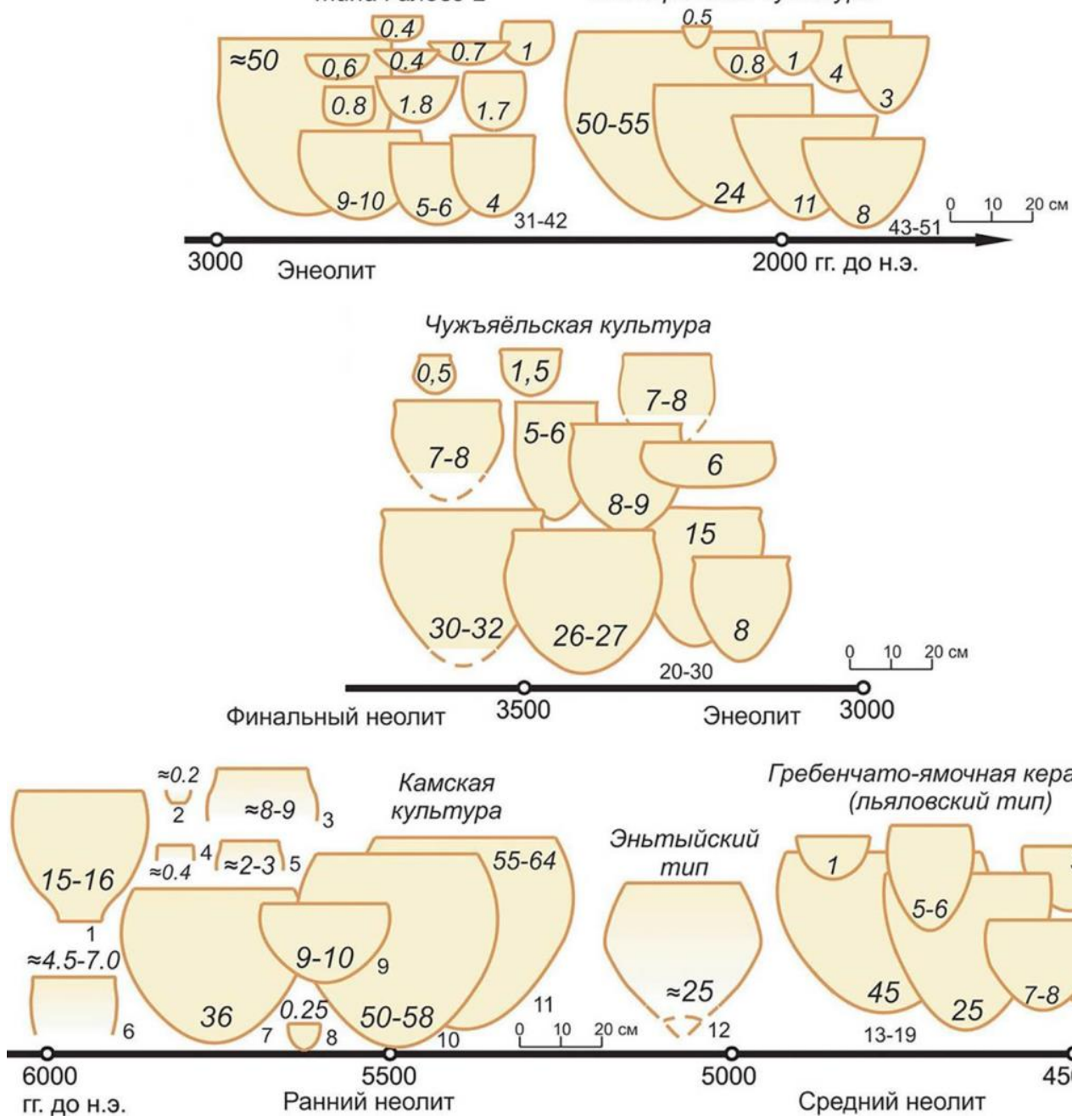

Камская

Камская
культура

Гребенчато-ямочная керамика (льяловский тип)
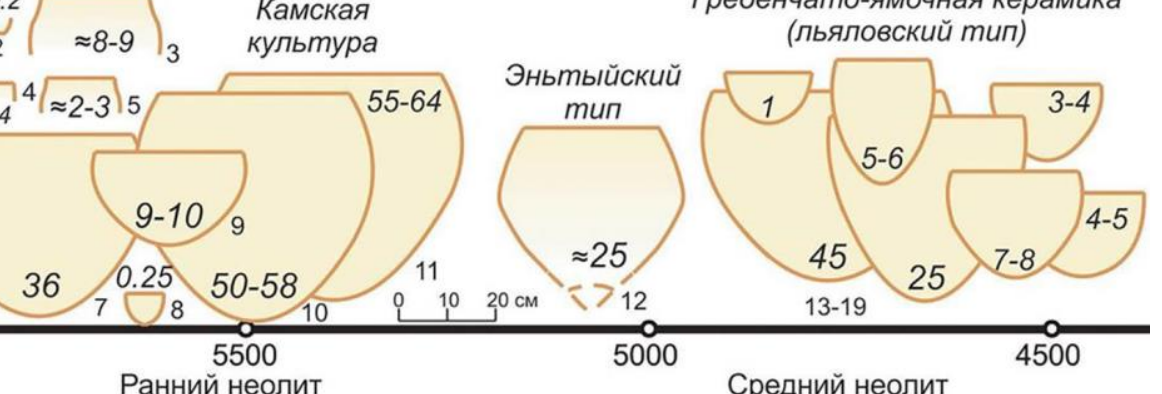

Рисунок 4 - Схема развития форм керамической посуды. Цифры курсивом обозначают объемы емкостей. 1 - Чудгудоръяг; 2-5- Конещелье; 6- Дутово 1; 7- Пезмог IV; 8-11- Кочмас Б; 12 - Эньты IA; 13-30- Ошчой V, жилище № 3; 31-42 - Галово II; 43-51- Чойновты II

Таблица 1 - Общая пропорциональность форм сосудов (отношение высоты сосуда к его диаметру)

\begin{tabular}{|l|c|c|c|c|c|c|}
\hline \multirow{2}{*}{ Пропорциональность } & $\begin{array}{c}\text { Ранний } \\
\text { неолит }\end{array}$ & $\begin{array}{c}\text { Средний } \\
\text { неолит }\end{array}$ & $\begin{array}{c}\text { Финальный неолит }- \\
\text { энеолит }\end{array}$ & Энеолит & Прочие & $\begin{array}{c}\text { Общее } \\
\text { количество }\end{array}$ \\
\cline { 2 - 7 } & Кол-во/\% & Кол-во/\% & Кол-во/\% & Кол-во/\% & Кол-во/\% & Кол-во/\% \\
\hline $0,2643-0,3534$ & 0 & 0 & $2 / 2,6$ & $6 / 9,4$ & 0 & $\mathbf{8 / 4 , 4}$ \\
\hline $0,3535-0,7069$ & $1 / 10$ & $5 / 21,7$ & $11 / 14,1$ & $25 / 39,1$ & $2 / 28,6$ & $\mathbf{4 4 / 2 4 , 2}$ \\
\hline $0,7070-1,413$ & $9 / 90$ & $18 / 78,3$ & $64 / 82,1$ & $33 / 51,6$ & $5 / 71,4$ & $\mathbf{1 2 9 / 7 0 , 9}$ \\
\hline $1,414-1,8$ & 0 & 0 & $1 / 1,3$ & 0 & 0 & $\mathbf{1 / 0 , 5}$ \\
\hline \multicolumn{1}{|c|}{ Всего } & $\mathbf{1 0 / 1 0 0}$ & $\mathbf{2 3 / 1 0 0}$ & $\mathbf{7 8 / 1 0 0}$ & $\mathbf{6 4 / 1 0 0}$ & $\mathbf{7 / 1 0 0}$ & $\mathbf{1 8 2 / 1 0 0}$ \\
\hline
\end{tabular}

Таблица 2 - Объемы керамических емкостей

\begin{tabular}{|l|c|c|c|c|c|c|}
\hline \multirow{2}{*}{ Объем емкостей, л } & $\begin{array}{c}\text { Ранний } \\
\text { неолит }\end{array}$ & $\begin{array}{c}\text { Средний } \\
\text { неолит }\end{array}$ & $\begin{array}{c}\text { Финальный неолит - } \\
\text { энеолит }\end{array}$ & Энеолит & Прочие & $\begin{array}{c}\text { Общее } \\
\text { количество }\end{array}$ \\
\cline { 2 - 7 } & Кол-во/\% & Кол-во/\% & Кол-во $\%$ & Кол-во/\% & Кол-во/\% & Кол-во/\% \\
\hline $0,05-2,5$ & $4 / 40,0$ & $4 / 14,8$ & $21 / 26,9$ & $32 / 50,0$ & $3 / 42,9$ & $\mathbf{6 4 / 3 5 , 2}$ \\
\hline $2,5-10$ & $3 / 30,0$ & $11 / 48,1$ & $19 / 24,4$ & $22 / 34,4$ & 0 & $\mathbf{5 5 / 3 0 , 2}$ \\
\hline $10-25$ & 0 & $6 / 25,9$ & $11 / 14,1$ & $6 / 9,4$ & $4 / 57,1$ & $\mathbf{2 7 / 1 4 , 8}$ \\
\hline Более 25 & $3 / 30,0$ & $2 / 11,1$ & $27 / 34,6$ & $4 / 6,2$ & 0 & $\mathbf{3 6} / \mathbf{1 9 , 8}$ \\
\hline \multicolumn{1}{|c|}{ Всего } & $\mathbf{1 0 / 1 0 0}$ & $\mathbf{2 3 / 1 0 0}$ & $\mathbf{7 8 / 1 0 0}$ & $\mathbf{6 4 / 1 0 0}$ & $\mathbf{7 / 1 0 0}$ & $\mathbf{1 8 2 / 1 0 0}$ \\
\hline
\end{tabular}




\section{Использование}

Как было сказано выше, условия залегания артефактов и экофактов в песке ограничивают сохранность данных. Количество сосудов с нагаром на их поверхности на известных нам памятниках ничтожно. Наиболее яркий пример - местонахождение Пезмог IV [31, с. 137], отличающееся, однако, условиями залегания керамики на глубине 3,6 м в состоянии, погребенном толщей отложений старичного и пойменного аллювия. Изредка на внутренней поверхности сосудов сохраняется равномерный налет нагара (днище сосуда Угдым IA, придонная часть сосуда Ниремки I, жилища № 12). Возможность сохранности липидов в керамике региона еще только выясняется. В связи с этим основной доступный материал сама керамическая посуда и ее археологический контекст. А такие сведения очень скудны. Так, в жилище № 3 поселения Чужъяёль I среди фрагментов развалов и под ними залегали древесные угли и мелкие части обугленной бересты [8, с. 27]. Развал сосуда объемом около 2 л в жилище Угдым IГ содержал обугленную бересту, а на одном участке внутренней поверхности под венчиком находились остатки клея, возможно, из березового вара. При этом следы ремонта отсутствовали. Это может указывать на использование сосуда для изготовления клея. Об использовании сосудов в металлообработке свидетельствует лишь один контекст - жилище № 7 поселения Галово II, где в кострище найдены ошлакованные емкости без орнамента [7, с. 66]. Таким образом, это ситуации, не связанные с приготовлением пищи или ее хранением, но предположим, что они сохранились только благодаря этой необычности их применения. Таким образом, мы не располагаем достоверными данными об особенностях использования керамической посуды в среде бродячих охотников изучаемого региона. Можно опираться только на данные об объемах сосудов и их пропорциональности.

\section{Результаты}

Несомненно, полученные расчеты удалены от реальности из-за негативного воздействия времени и ненамеренных действий первобытного человека, но они позволяют уйти от эмоциального восприятия материала и более объективно судить об описываемом явлении. Может показаться, что бродячие охотники Крайнего Севера очень робко включают керамическую посуду в свой обиход. Но на самом деле в масштабах эпохи камня это происходит стремительно: от древнейших проявлений использования керамики до появления привычных наборов и форм посуды проходит меньше тысячелетия. Выявленные ситуации ее отсутствия на стоянках неолита и энеолита сравнительно немногочисленны и могут быть связаны с видом протекавшей на них деятельности (например, кремнеобработкой), не предполагающих обязательного использования посуды. Все это указывает на ее востребованность даже у очень небольших мобильных групп населения. Однако потребность в керамике также имеет свои пределы, о чем свидетельствует количество использованных емкостей, их характеристики и контекст. Это может объясняться кратковременностью обитания на известных стоянках или в жилищах, количеством проживающих в них людей.

Преобладающие в разных культурах неолита и энеолита сосуды свидетельствуют об использовании привычных для всей лесной зоны круглодонных горшков, чаш и мисок - простейших форм без излишеств. Отклонения от этого канона - часть древнейшей керамики региона и, возможно, единичные сосуды из необыденных контекстов. Анализ объемов реконструированных емкостей указывает на преобладание посуды для индивидуального и коллективного потребления и/или приготовления пищи. В контекстах, где керамика имеет сравнительно хорошую сохранность, представлены порой целые наборы посуды от миниатюрных сосудов до горшков объемами 30-40 л. Однако крупные емкости, которые могли использовать для хранения, представлены в меньшем количестве. Их большее число характеризует чужъяёльскую культуру финального неолита и энеолита, в то время как в раннем неолите практически вся посуда имеет малые объемы. Для гаринской традиции энеолита характерно доминирование малых и средних объемов при возросшей доле мискообразных емкостей.

Разнообразие форм древнейшей керамики, особенно «забегание вперед» в виде горшка из местонахождения Пезмог IV (и, возможно, сосудов Кочмас Б) указывает на распространение в регионе уже сформированных навыков гончарства вместе с их носителями. И их источники различны, что подтверждают и данные изучения каменных инвентарей, сопровождающих различные виды посуды [25, с. 2645]. Да и в последующие периоды мы можем наблюдать внезапные проявления в регионе традиций, не имеющих связи с предшествующими. Наиболее впечатляющее из них - чужъяёльская культура, изучение феномена которой, возможно, позволит ответить на некоторые поднятые в статье вопросы.

\section{Перспективы}

Предпринятая в этой работе попытка по обобщению и систематизации доступных данных о керамической посуде на памятниках неолита и энеолита Крайнего северо-востока Европы - лишь первый шаг. За ним должно последовать сопоставление этих сведений о керамике и о других видах источников с прицелом на установление зависимостей между ними (если таковые могут быть выявлены). Ведь керамическая посуда сравнительно быстро включается в уже существовавшую тысячелетиями материальную культуру с орудиями и утварью, изготовленными преимущественно из натуральных материалов. Ее начинает использовать население с образом жизни, который складывался также очень долго. Каковы причины такого обновления материальной культуры? Какова его роль в наблюдаемых нами изменениях этой культуры? Вот те основные вопросы, на которые надо попытаться ответить с использованием доступных в настоящее время методов и приемов.

\section{Список литературы:}

1. Цетлин Ю.Б. Теория и методы историко-культурного подхода. М.: ИА РАН, 2012. 430 с.

2. Eerkens J.W. Residential Mobility and Pottery Use in the Western Great Basin // Current Anthropology. Vol. 44, № 5 (December 2003). P. 728-738.

3. Сорокин А.Н. Пролог. М.: ИА РАН, 2013. 144 с.

4. Археология Республики Коми. М.: ДиК, 1997. $759 \mathrm{c}$. 
5. Simms S.R., Bright J.R., Ugan A. Plain-ware ceramics and residential mobility: a case study from the Great Basin // Journal of archaeological science. 1997. Vol. 24. P. 779-792.

6. Конаков Н.Д. Коми охотники и рыболовы во второй половине XIX - начале XX в. Культура промыслового населения таежной зоны Европейского Северо-Востока. М.: Изд-во «Наука», 1983. 249 с.

7. Лузгин В.Е. Древние культуры Ижмы. М.: Издво «Наука», 1972. 128 с.

8. Стоколос В.С.Древние поселения Мезенской долины. М.: Изд-во «Наука», 1986. 191 с.

9. Стоколос В.С. Культуры эпохи раннего металла Северного Приуралья. М.: Изд-во «Наука», 1988. $256 \mathrm{c}$.

10. Стоколос В.С. Энеолит и бронзовый век // Археология Республики Коми. М.: ДиК, 1997. С. $213-$ 245.

11. Логинова Э.С. Поселение Эньты I // Археологические памятники эпохи палеометалла в Северном Приуралье: материалы по археологии Европейского Северо-Востока. Вып. 7 / отв. ред. В.С. Стоколос. Сыктывкар: Коми филиал АН СССР, 1978. С. 3-22.

12. Логинова Э.С. Поселение Эньты II // Памятники материальной культуры на Европейском Северо-Востоке: материалы по археологии Европейского Северо-Востока. Вып. 10 / отв. ред. Э.А. Савельева. Сыктывкар: Коми филиал АН СССР, 1986. С. 45-53.

13. Логинова Э.С. Поселения на Средней Вычегде в эпоху неолита // Научные доклады. Вып. 120. Сыктывкар: Коми филиал АН СССР, 1989. 24 с.

14. Логинова Э.С. Поселение Юванаяг на Нившеpe // Этнокультурные контакты в эпоху камня, бронзы, раннего железа и средневековья в Северном Приуралье: материалы по археологии Европейского Северо-Востока. Вып. 13. Сыктывкар: Коми НЦ УрО PAH, 1995. C. 43-58.

15. Королев К.С. Население Средней Вычегды в древности и средневековье. Екатеринбург: УрО РАН, $1997.196 \mathrm{c}$.

16. Семенов В.А., Несанелене В.Н. Европейский Северо-Восток в эпоху бронзы (по материалам раскопок Сыктывкарского университета): учебное пособие. Сыктывкар: Сыктывкарский ун-т, 1997. 172 с.

17. Верещагина И.В. Структура поселений мезолита - раннего металла на северо-западе России (бассейн Северной Двины) // Записки Института истории материальной культуры. 2008. № 3. С. 118-136.

18. Верещагина И.В. Мезолит и неолит Крайнего европейского северо-востока. СПб.: Петербургское Востоковедение, 2010. 232 с.

19. Косинская Л.Л. Керамика поселения Ниремка I // Памятники материальной культуры на Европейском Северо-Востоке: материалы по археологии Европейского Северо-Востока. Вып. 10 / отв. ред. Э.А. Савельева. Сыктывкар: Коми филиал АН СССР, 1986. C. 35-44.

20. Косинская Л.Л. Жилища эпохи ранней бронзы в бассейне Вычегды // Советская археология. 1987. № 1. С. 243-249.

21. Косинская Л.Л. К вопросу о характере хозяйства населения бассейна р. Вычегды в эпоху энеолита - ранней бронзы // Энеолит лесного Урала и Поволжья / отв. ред. Л.А. Наговицын. Ижевск: Удмуртский ИИЯЛ АН СССР, 1990. С. 120-131.
22. Косинская Л.Л. Неолит // Археология Республики Коми. М.: ДиК, 1997. С. 146-212.

23. Паршуков Ю.В. Дань-Дар - новый энеолитический памятник на средней Вычегде // Памятники эпохи камня, раннего металла и средневековья Европейского Северо-Востока: материалы по археологии Европейского Северо-Востока. Вып. 17 / отв. ред. Э.А. Савельева. Сыктывкар: Изд-во Коми НЦ УрО PAH, 2005. C. 23-33.

24. Паршуков Ю.В. Технология керамики эпохи энеолита-бронзы Вычегодского края // Научные доклады. Вып. 508. Сыктывкар: Коми НЦ УрО Российской академии наук, 2010. 44 с.

25. Карманов В.Н. Неолит Европейского СевероВостока. Сыктывкар: Коми научный центр УрО РАН, 2008. $226 \mathrm{c}$.

26. Карманов В.Н. Новые данные по домостроительству населения Крайнего северо-востока Европы в эпоху раннего металла // Вестник Пермского университета. Серия «История». 2017. Вып. 1 (36). С. 26-40.

27. Буров Г.М. Нео-энеолитические полуземлянки Крайнего северо-востока Европы в аспекте социальной организации его древнего населения // Вопросы археологии Урала. Вып. 21. Екатеринбург: УрО РАH, 1993. С. 23-41.

28. Косинская Л.Л. О типах поселений эпохи камня на Европейском Северо-Востоке // Вопросы археологии Урала. Вып. 21. Екатеринбург: УрО РАН, 1993. C. 41-59.

29. Карманов В.Н. Неолитическое население на европейском северо-востоке: обитание или пребывание? // Первобытные древности Евразии. К 60-летию Алексея Николаевича Сорокина / отв. ред. С.В. Ошибкина. М.: ИА РАН, 2012. С. 421-449.

30. Косинская Л.Л. Неолитическая стоянка-мастерская на Выми // Проблемы этногенетических исследований Европейского Северо-Востока: межвуз. сб. науч. тр. / отв. ред. Р.Ф. Итс. Сыктывкар: Сыктывкарский ун-т, 1982. С. 132-144.

31. Волокитин А.В., Карманов В.Н., Зарецкая Н.Е. Новые данные по хронологии камской неолитической культуры // Российская археология. 2006. № 1. C. $137-142$.

32. Karmanov V.N., Zaretskaya N.E., Volokitin A.V. Another Way of Early Pottery Distribution in Eastern Europe? Case Study of the Pezmog 4 Site, European Far Northeast // Radiocarbon. 2014. Vol. 56, № 2. P. 733-741.

33. Логинова Э.С. Опыт выделения ранненеолитического жилища на поселении Эньты I (Средняя Вычегда, Республика Коми) // Проблемы археологического изучения северо-востока Европы: материалы по археологии европейского северо-востока. Вып. 20 / отв. ред. И.О. Васкул. Сыктывкар: ИЯЛИ Коми НЦ УрО РАН. 2018.

34. Косинская Л.Л. Поселение Ревью I // Проблемы археологического изучения северо-востока Европы: материалы по археологии европейского северовостока. Вып. 20 / отв. ред. И.О. Васкул. Сыктывкар: ИЯЛИ Коми НЦ УрО РАН. 2018.

35. Сидоров В.В. Реконструкции в первобытной археологии. М.: Ин-т археологии РАН, ТАУС, 2009. $216 \mathrm{c}$.

36. Логинова Э.С. Отчет о полевых исследованиях Вишерского археологического отряда в 1985 году. Сыктывкар, 1986 // Научный архив института археологии РАН. Р-1. № 10779, № 10779а. 
37. Верещагина И.В. Ранний неолит на Северной Двине // Археологические памятники Печоры, Северной Двины и Мезени: материалы по археологии Европейского Северо-Востока. Вып. 6 / отв. ред. В.С. Стоколос. Сыктывкар: Коми филиал АН СССР, 1977. C. 31-36.

38. Карманов В.Н. Стоянка Зубово - памятник с накольчатой керамикой на Мезени (Архангельская обл.) // Проблемы изучения эпохи первобытности и раннего средневековья лесной зоны Восточной Европы: к 60-летию А.В. Уткина. Вып. 4 / под ред. Е.Л. Костылёвой и В.А. Аверина. Иваново: Издатель Ольга Епишева, 2015. С. 66-71.

39. Косинская Л.Л. Неолитическая стоянка Кочмас на Нижней Вычегде // Неолитические памятники Урала: сб. науч. тр. Свердловск: УрО АН СССР, 1991. С. 4-20.

40. Зеленский В.С. Памятник эпохи бронзы Синегорье на Цильме // Первобытные и средневековые древности европейского северо-востока: материалы по археологии европейского северо-востока. Вып. 19
/ отв. ред. А.В. Волокитин. Сыктывкар: ИЯЛИ Коми НЦ УрО РАН, 2015. С. 39-52.

41. Цетлин Ю.Б. Керамика. Понятия и термины историко-культурного подхода. М.: ИА РАН, 2017. $346 \mathrm{c}$.

42. Грязнов М.П. Техника графической реконструкции формы и размеров глиняной посуды по фрагментам // Советская археология. М.-Л.: Изд-во академии наук СССР, 1946. С. 306-318.

43. Цетлин Ю.Б. Понятие качества для анализа объема сосудов // Краткие сообщения института археологии. Вып. 239. М.: Языки славянской культуры, 2015. C. 393-408.

44. Косинская Л.Л. Ранняя гребенчатая керамика в неолите Зауралья // Уральский исторический вестник. 2014. № 2 (43). С. 30-40.

Исследование выполнено в рамках научно-исследовательской работы «Археологическое наследие европейского северо-востока России: выявление, научное описание и систематизация", №ГР 0417-2015-0031.

\section{CERAMIC WARE IN THE CULTURE OF MOBILE FORAGERS OF THE EXTREME NORTH-EAST OF EUROPE}

(C) 2018

Karmanov Victor Nicolaevich, candidate of historical sciences,

head of Preservation and Popularization of Archaeological Heritage Sector

Institute of Language, Literature and History

of Komi Scientific Centre of the Ural Branch of the Russian Academy of Sciences (Syktyvkar, Russian Federation)

Abstract. In the paper the author summarized and systematized the initial data on ceramic ware of the Neolithic and Eneolithic of the Extreme north-east of Europe. He analyzed information about the archaeological contexts of ceramics, its quantitative (number of capacities in each complex) and qualitative (shape, proportionality and volume of vessels) characteristics. Critical analysis is used to assess the possibilities of available materials to extract information. As a result, the dynamics of quantitative and qualitative parameters of ceramic ware during the VI - first half of II millennium $\mathrm{BC}$ was traced. Its cultural and chronological features are determined as well. It is established that in the first half of the $\mathrm{V}$ millennium $\mathrm{BC}$ ceramics in the form of sets of vessels of different volumes and kinds becomes an integral part of the daily life of the hunters of the region. According to their lifestyle, the demand for ceramics was limited: the average number of simultaneously used vessels on average 3-4 containers per context. In this case, the simplest forms (round-bottomed pots with volumes up to 25 liters and bowl-shaped dishes up to 2,5 liters) predominate. Ceramic traditions presented in the region are associated with cultures that originate in different adjacent areas of the forest zone of Eastern Europe and Western Siberia, so the universality of the customary forms, volumes and, probably, the ways of using ceramic dishes, is universally accepted. The data obtained can be used as materials for the development of the problem of the distribution of early ceramics, for assessing the role and determining the place of it in the material culture of the prehistoric population.

Keywords: prehistoric culture; archaeology; archaeological data; archaeological context; site; habitat; hunting camp; settlement; subterrain dwelling; assemblage; hearth; Neolithic; Eneolithic; extreme north-east of Europe; ceramics; ceramic ware; form of vesells; volume of capacity.

УДК 903.01

Статья поступила в редакцию 19.06 .2018

\section{КОСТЯНОЙ И РОГОВОЙ ИНВЕНТАРЬ ПАМЯТНИКОВ РАННЕГО НЕОЛИТА ДНЕПРО-ДВИНСКОГО МЕЖДУРЕЧЬЯ: ТЕХНОЛОГИЧЕСКИЕ И ФУНКЦИОНАЛЬНЫЕ ОСОБЕННОСТИ, КОНТЕКСТ}

(C) 2018

Малютина Анна Андреевна, младший научный сотрудник экспериментально-трасологической лаборатории Институт истории материальной культуры РАН (2. Санкт-Петербург, Российская Федерация)

Аннотация. В данной статье представлены результаты трасологического исследования костяного и рогового инвентаря, полученного в результате раскопок памятников раннего неолита на территории ДнепроДвинского междуречья. Подобное исследование проводится впервые для данной категории археологического материала. Для анализа было отобрано 27 предметов из кости, рога и зубов, происходящих с двух памятников Сертейского микрорегиона - Сертея X и Рудня Сертейская. Хорошая сохранность изделий позволила изучить макро- и микроследы, связанные с технологией обработки сырья и получения изделий, способы ис- 